\title{
Assessing and addressing energy vulnerability at the community scale: an interpretive case study
}

\author{
Janice Astbury and Sandra Bell* \\ Durham University
}

\begin{abstract}
The paper adopts a whole systems framework to identify and track efforts by local government and community organisations to address issues of energy vulnerability among residents in an urban borough. When viewed through the lens of energy justice these activities appear to disappoint or not to reach all types of people they are intended to benefit. Problems arise in part because the system is fractured, lacking coordination and complementarity, and also because of a failure to account for the multiple and dynamic features of energy vulnerable clients. A whole systems approach combined with a social justice perspective offers a diagnostic tool for identifying ineffective practices and points towards the creation of better integrated and thorough methods for delivering sustainable interventions.
\end{abstract}

Keywords: energy vulnerability, fuel poverty, energy justice, community organisations, local government.

\section{Introduction}

Why do locally led interventions intended to address energy vulnerability in the UK tend to fall short of expectations? For example a recent study of twelve such intervention projects found them to be affected by 'lack of resources, access to local authority data and knowledge of appropriate engagement methods' (Reeves, 2016: 17). Furthermore these projects struggled to recruit volunteers; lacked secure funding opportunities and were rarely competent in evaluating impact (ibid.). Other studies show that lack of sufficient resources to see an intervention through to its conclusion is an elementary but obstinate barrier; for example, rationing energy advisors to a single visit to an energy vulnerable household (Fischer et al., 2014). Moreover, multiple sectors implicated in delivering sustainable solutions locally struggle to communicate effectively (Shortt and Rugkåsa, 2007: 99), leading researchers to conclude that interventions require specifically assigned, well resourced managers dedicated to crossing social and institutional boundaries (Rugkåsa et al., 2007).

In this article we do not challenge these causes of unsatisfactory results or the validity of the authors' recommendations. Indeed, we demonstrate how our experiences support their conclusions. In addition, however, we consider the ways in which interventions are affected by the dynamic qualities of urban communities and the diverse problems associated with the energy vulnerable households they are home to. We examine local authority and community organisation delivery of support to 
energy vulnerable households. When both kinds of organisations work together, or when community organisations work independently of the local authority, we refer to an initiative as being community led. In our example, located in an urban setting, a variety of separate, largely unrelated projects were simultaneously trying to address energy vulnerability, resulting in fragmentation and loss of benefits that might be expected to flow from a better integrated system.

We propose that researchers seeking to understand and evaluate energy vulnerability interventions and practitioners who design and deliver them can benefit from adopting a whole systems perspective. We further argue that such a holistic overview of relations between community organisations, alongside local government departments, can be supported by adopting a social justice perspective to expand our comprehension of energy vulnerability.

The social justice model used is based on identifying deficiencies and benefits across three dimensions of justice: distributional, procedural and recognition justice (Walker and Day, 2012). Based on findings from qualitative research we argue for considering equity and inclusiveness within a whole system approach (Jenkins et al., 2014) as a way for community organisations and local authorities to improve outcomes for energy based interventions that might also contribute to wider social, economic and health objectives.

We begin with a brief explanation of how household deprivation relating to energy has been conceived. Understandings are shifting from a notion of fuel poverty that emphasises lack of heating, or incapacity of the dwelling to retain it, to a more broadly encompassing model referred to as energy vulnerability. Our next step is to explain our adoption of a systems approach towards the reframing of energy vulnerability through the lens of social and environmental justice (Simcock, Walker and Day, 2016). We devote the third section to a summary of empirical research findings, which we follow with an assessment of their implications, especially with regard to future practice.

\section{From fuel poverty to energy vulnerability}

The term fuel poverty was coined by Brenda Boardman in 1991 to apply to any household unable to ensure 'adequate energy services for 10 percent of its income' (Boardman, 1991: 227). Boardman identified the root cause 'as a result of insufficient capital expenditure on improving the calibre of the home' (Boardman, 2013: xv). This fundamental flaw makes a home 'difficult to heat' so the poorest households have 'to buy the most expensive warmth' (ibid.). Boardman's '10 percent definition' of fuel poverty is still used in Scotland, Wales and Northern Ireland. In 2013 for England the definition was changed to one of 'Low Income High Cost' (LIHC). Under this rubric, a household is considered fuel poor when costs are calculated to be above the national median level; and on meeting that cost for energy the household is left with a residual income below the official poverty line. Under the LIHC definition, official statistics estimated that in 201511 per cent (2.5 million) of English households were in fuel poverty, an increase of 0.4 percent from 2014 (BEIS, 2017b: 3).

Boardman traced fuel poverty to three related factors: inadequate insulation and heating systems, low incomes, and high energy costs (1991). It is most prevalent in households on low incomes, and among people with children under the age of 16 , people with disabilities or suffering from a long-term illness and older people (NEA, 2015). The effects include: health problems related to cold and damp; increased health costs; excess winter deaths (the difference between the number of deaths which occur December to March and the average number of deaths during the preceding and 
subsequent four months); indebtedness; mental stress; low attainment levels for children; social exclusion/isolation; and a detrimental impact on local economies (Ibid.).

Recently researchers argued for expanding the scope of analysis associated with fuel poverty, asserting that people need energy services not only directly to combat ill health (Middlemiss and Gillard, 2015: 147). Everyone requires certain levels of comfort to be able to invite others into their homes; to wash and dress in clean clothes and render themselves socially acceptable to access education and employment opportunities, as well the ability to use energy services for communication and entertainment. It is, however, important to note that meeting these necessities can have an indirect effect on health status. For example, Grey et al (2017: 140) show how energy efficiency investment in low income homes 'increased subjective well-being and were linked to a number of psychosocial intermediaries that are conducive to better health'.

Thinking in terms of energy services points to how deprivation in the home is embedded not only in resources for its upkeep, but also in appliances, infrastructures, social norms and human action (Bouzarovski et al., 2014: 16). Access to energy services, including but moving beyond heating, is thus 'a matter of justice, or of what constitutes the basic rights and entitlements of a sufficient and healthful everyday life' (Walker and Day, 2012: 69).

Energy vulnerability is 'the propensity of an individual to become incapable of securing a materially and socially needed level of energy service in the home' (Bouzarovski et al., 2014: 10) due to 'ineffective operation of the socio-technical pathways that allow for the fulfilment of household energy needs' (Bouzarovski and Petrova, 2015: 31). This 'propensity' may be due to changes in a person's situation, but also through changes in technology or in policy change such as the 1989 privatisation of the energy sector in the UK (Pearson and Watson, 2012: 33).

Our case study is informed by Day and Walker's (2013) understanding of energy vulnerability as a problem of social injustice, while our research approached community led initiatives by focusing as much on the relations among them as on their individual schemes.

\section{Creating a systems framework for energy justice research}

Ison (2008) provides a lengthy overview of the history of systems thinking, which he views as emanating from separate lineages that share a common grounding in their focus on dynamic relationships. He makes an illuminating distinction between different strands of systemic thinking and systematic thinking. Ison proposes that the latter is exemplified by medical students' courses on anatomy. These often take 'a systematic approach to the study of the human body - the hand, leg, internal organs etc. - but at the end of their study they may have very little understanding of the body as a whole because the whole is different to the sum of the parts' (Ison, 2008: 140). Systemic thinking resolves this problem by concentrating on the connections between things. A researcher can use techniques such as social mapping to formulate 'a system of interest in a situation, i.e. a process' (ibid.) as a focus for enquiry. For us the system of interests was represented by a constellation of endeavours among a local authority and community organisations to address energy vulnerability.

Atwood et al. (2003: 9) identify four key dilemmas that need to be reconciled by social researchers trying to fathom system processes. These dilemmas include resolving top-down and bottom-up approaches within organisations; the tension 
between people as consumers and as citizens; the tension between treatment and prevention and the lines between consultation and involvement of service users in resolving social problems (Ibid.). All of these dilemmas were present during our research. For example, the local authority's fuel poverty officer was inclined to view clients as consumers and to concentrate on technical solutions that might not provide the most appropriate resolution for service users, whose energy vulnerability was not examined in the wider context of their economic circumstances and daily practices. Whereas community organisations would often gain a better understanding of a client's overall circumstances but could not offer access to expensive technical solutions in instances when they would have been helpful.

Ison (2008: 142) suggests the use of the term systems of interest as a way of avoiding confusion with the everyday use of the word 'system'. It is a device for 'distinguishing a system in a situation, in relation to an articulated purpose, in which an individual or a group has an interest (a stake)' Systems of interest are thus not to be treated as neatly or impenetrably bounded. Our system of interest delineated endeavours to tackle energy vulnerability within the geographical and administrative confines of a single local authority area situated within a larger urban context. But, inevitably, these boundaries were transgressed in significant ways. Systems are situated within wider systems, meaning that it is unrealistic to ignore what lies outside a system. Our case study is positioned within a conurbation and subject to wider economic and political forces. We therefore applied Boardman and Sauser's advice (2008: 24) to adopt 'intelligent walls' in defining the boundaries for our 'scope of interest'. For example, it was inescapable that the actions of local authority personnel were governed by policies emanating from a national politico-economic order, and that community organisations had to adhere to rules set by funding schemes emanating from elsewhere.

Jenkins et al (2014: 74) make the case for 'a re-conceptualisation of energy justice that includes a systems perspective at its core using the example of fuel poverty.' They advocate 'the utility of combining a whole systems approach with the burgeoning concept of energy justice' (2014: 83). This approach treats the consumption and production of energy from resource extraction to waste disposal as a social-technical entity responsible for complex forms of energy injustices across different scales. The authors advocate an interactionist understanding that focuses 'on the impacts of the relationships between the governors and the governed and the moments at which there is a possibility to intervene and steer the system' (2014: 81). Our research treats community-led initiatives in a metropolitan borough as a sub-system of energy governance. In this respect we also draw on Pratt et al.'s (1999) treatment of organisations as systems. They describe a system as constituted by people and organisations who connect around a shared purpose creating 'a perceived whole whose essential properties arise from the relationship between its parts' (Ibid.: xiv).

Walker and Day (2012) note three forms of injustice and their component parts in fuel poverty: procedural injustice, distributional injustice and injustice in recognition. 
Figure 1: Three forms of injustice and their component parts in fuel poverty (Walker \& Day 2012, p. 74)

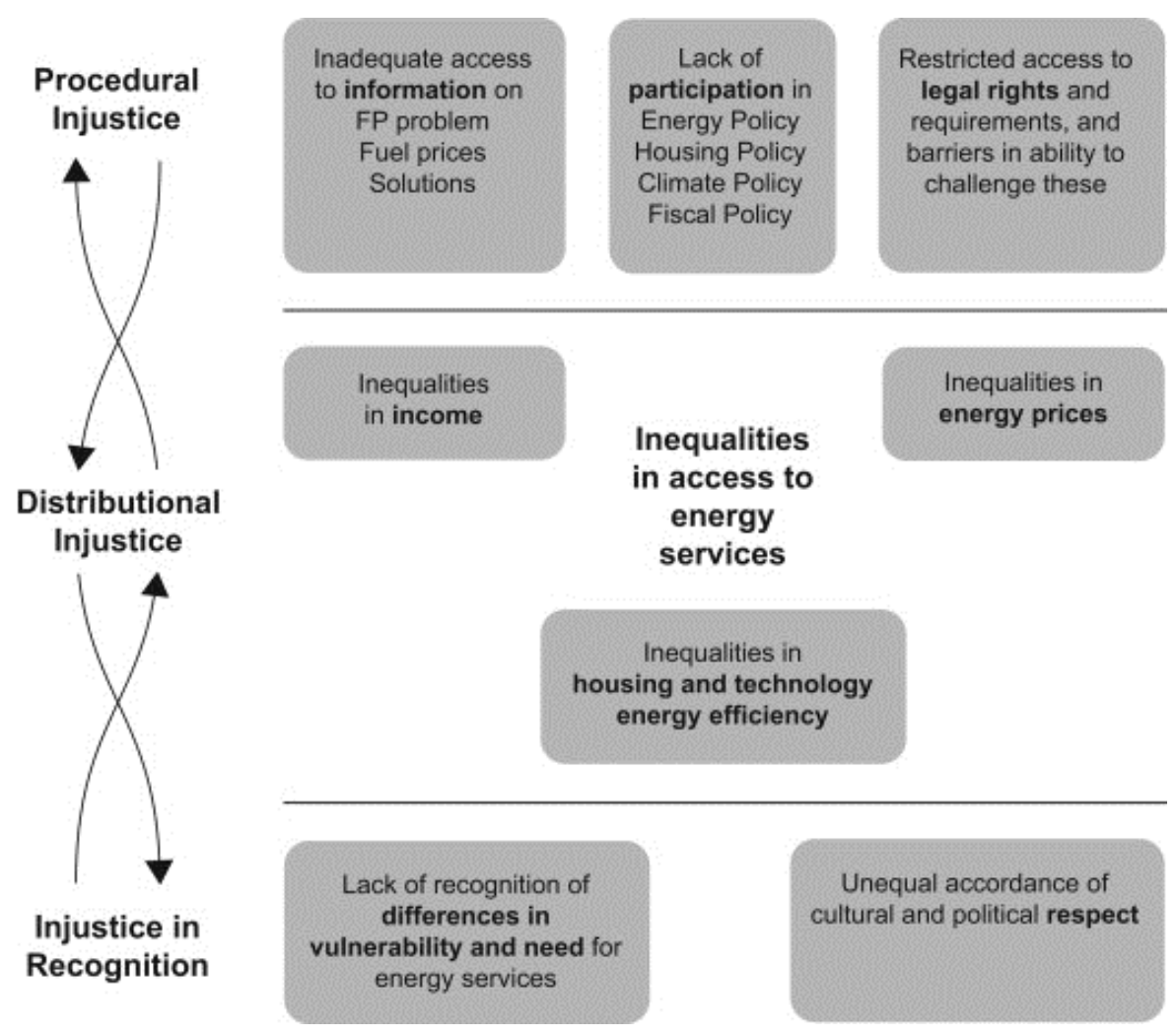

Whereas previous analyses of fuel poverty focused on distributional injustice (Goldthau and Sovacool, 2012), Walker and Day (2012) demonstrate that social justice for energy requires a broader conception of justice. For instance, procedural injustice relates to access to information about how to obtain cheaper energy and energy efficient housing, or recourse when one is unjustly treated by an energy supplier or housing provider. Moreover, the roots of injustices in policies and structures limit the ability of vulnerable sectors of society to influence decisions that affect them. Injustice in recognition corresponds to situations where the voices of some people are muted, their lives less valued because they are elderly, or deemed blameworthy for being poor.

Disaggregating the three categories of social justice is useful as a tool for probing the multifaceted nature of energy vulnerability. But here too connections should not be neglected: as Gillard et al. (2017: 54) point out, the three categories are 'often coextant and mutually reinforcing' in the sense that one leads to the other.

\section{Co-Produced Research}

We established our energy research partnership with a metropolitan borough council through a pre-existing wider collaboration between the council and our university. After initial discussions we arrived at the decision to focus research on the role of community organisations and their capacity to complement the efforts of other actors, including local and national government and energy suppliers. These issues related to the Council's identification of community organisations as significant for assisting them 
to meet desirable non-statutory goals for the alleviation of energy vulnerability, in circumstances of shrinking budgets. For inclusion in our study a community organisation was defined as a formally constituted not-for-profit organisation situated wholly, or through a branch, within the borough and intended to serve its residents. These organisations were staffed by both paid and voluntary participants who may or may not have been resident within the boundaries of the borough.

This work borrows from a method initially deployed in workshops with stakeholders in rural County Durham, UK, to develop a tool to support community decision making about micro-generation options. An Energy Equity Assessment Tool takes the three dimensions of social justice and applies them to analysing the equity dimensions of energy technologies at a whole systems level (Adams et al., 2012). These six themes social rights and responsibilities, energy needs, technology, policy and economic markers, time and geography were generated heuristically by a wide range of interdisciplinary stakeholders for use by groups of decision makers when assessing the equity aspects of micro-generation projects. The themes were devised to act as prompts for discussions that unfold in an iterative fashion to produce a thorough account of the implications of a proposed community energy project as it might affect all members of a village or neighbourhood. The usefulness of the themes was subsequently tested at separate workshops with residents of two County Durham villages who were planning energy projects intended to benefit their respective communities (Adams and Bell, 2015). We adopted the six themes and the whole systems perspective for assessing energy equity as a checklist for testing the capacity of a borough-level community system for ameliorating energy vulnerability.

In line with our whole systems approach we took a wide ranging perspective on how energy vulnerability might be addressed, including projects helping low income groups to grow food, or encouraging cycling rather than paying for transport. Such alternatives can have positive effects on health and well-being and in many cases contribute to building social relations, all of which can increase capacity to confront the challenges of energy vulnerability (Middlemiss and Gillard, 2015: 153). This meant acknowledging community initiatives that address energy justice more indirectly.

The empirical research for this paper was undertaken during eight months in 2015 and a further twelve months in 2016-2017. In order to concentrate on relations between actors we deployed research methods described by Ison (2008), such as systems mapping, to formulate and explore a system of interest and the construction of a rich picture through ethnographic research.

During both stages of the research we worked in partnership with the local government authority. This partnership was important for facilitating researcher access to people who were experiencing and responding to energy vulnerability in the borough. Council staff and university researchers defined the research together and collaborated closely in its implementation and in reflecting on emerging findings and how to apply them. The ethnographic approach was adopted throughout in order to reveal the variety and complexity of energy vulnerability and the delivery of interventions intended to address it.

The university researcher conducted interviews (22 with 18 distinct individuals) and informal conversations with council staff and shadowed them at work. The same methods were applied to community organisation staff and volunteers (31 interviews with 25 distinct individuals) with the researcher accompanying these actors in a range of activities related to energy vulnerability including home energy visits (18), energy advice provision, training, workshops and meetings (participant observation at 24 events). Interviews were recorded via note taking and analysed along with field notes by searching for emergent key themes and informants' responses to them. 
During the second stage of research we recruited and trained four participants from community organisations dealing with energy vulnerability and one Council staff member. Training took place at two half day events and at regular monthly meetings (seven in total). The community researchers conducted interviews with clients who they visited in their homes where they were able to examine energy related problems at first hand and track the progress and the effects of interventions that sought to ameliorate their energy vulnerability. The community researchers visited before and after the interventions took place and phoned in between to check progress. The visits and calls were recorded using forms that were submitted to the senior researchers and reflected upon during the monthly meetings.

Through these interactions, we developed portraits of the experience of energy vulnerability and of the organisations and interventions attempting to respond. These were characterised in terms of the three dimensions of justice and organised into a community system map. The system map was illustrated using the presentation application Prezi which allows viewers to zoom in to the detail and out to the broader system thus enabling visualisation of linkages among component parts. (See anonymised example

at http://prezi.com/r nxh3r 9fij/?utm campaign=share\&utm medium=copy\&rc=exOsha re). The system map enabled analysis and facilitated discussion and sharing of results when we presented it at a stakeholder workshop and made it freely available online.

\section{Characterising Energy Vulnerability}

According to government statistics, what they refer to as fuel poverty affected 12.6 per cent of households in the borough in 2015 (BEIS, 2017a: Table 2), a figure that has increased in recent years. Statistics foreground issues of distributional and procedural justice inviting researchers to probe beneath them to discover the actual predicaments facing households. We discovered these two forms of injustice to be directly, consciously and consistently experienced by energy vulnerable people. In researching the community workers and volunteers we were struck by their preoccupation with recognition justice. This group spent a lot of time and effort thinking about how to find and engage the different groups of people who are experiencing distributive and procedural injustice.

According to 2011 Census data 58.2 per cent of households in the case study borough were living in social and private rented accommodation. 17 per cent of households lived in council accommodation, 10 per cent in housing association properties, 30 per cent in private rented and 40 per cent were owner occupiers. Statistics documented by the borough council in 2013 showed the number of people living in private rented accommodation to be increasing, with repercussions for energy vulnerability. In England, 38 per cent of all households experiencing fuel poverty live in privately rented homes (BEIS, 2017b: 3). Average rents in this sector are 60 per cent higher than in the social rented sector (MHCLG, 2017), leaving a lower proportion of household income to spend on energy. Furthermore, the private rented sector has a greater proportion of energy inefficient homes than other tenures (MHCLG, 2017).

Increased demand for rented accommodation has led tenants, especially of private landlords, to feel insecure and fearful of asking for improvements in case this leads to rent increases or even eviction for being a nuisance tenant (Bone, 2014). Our informants cited unresponsive, exploitative and punitive behaviours on the part of landlords. Sometimes landlords controlled payment for energy (including through coin operated meters and inclusion of energy costs in rent) and abuses by private landlords where tenants were charged more than the real cost of the energy were mentioned by 
community organisation staff. Otherwise, landlords simply failed to inform or assist tenants in energy-related matters: "No information is provided about how to work the heating, or about who is the energy supplier, often they find themselves having to pay bills of a previous tenant or even for the wrong flat.' (participant in stakeholder meeting, January 2015). Community organisations reported tenants being reluctant to lodge complaints or request energy efficiency measures for fear of repercussions, including so-called 'revenge eviction'.

Private rented homes are more likely to have a low Energy Performance Certificate (EPC) rating than social sector homes; respectively 6 per cent compared to 1 per cent were in the lowest bands ( $F$ and G) in 2015 (DCLG, 2017). (From 1 April 2018, private sector landlords must ensure that their properties have an EPC rating of at least band $E$ before granting a tenancy to new or existing tenants.) However, the EPC was rarely understood or referred to as pertinent by clients seeking energy advice. The Council's fuel poverty officer remarked: 'People have never heard of an EPC, never mind know how to read one.'

By accompanying the local authority and community organisation energy advisors on visits and through our interactions with community organisations we concluded that residents in the poorest parts of the borough struggle to cope with a complex energy market. The range of providers, tariffs and payment schemes bewildered people: a problem that is compounded by levels of literacy and language barriers in a borough where approximately 130 languages are spoken. Community organisation staff told us that they had encountered children charged with dealing with bills and interacting with providers. As a community organisation staff member proclaimed, 'It's so easy to switch [providers] according to the government, they have no idea of the problems of ESOL [English as a Second or Other Language] and IT [Information Technology]!' (community organisation manager 1). The fact that in some instances language barriers create difficulties for efficient household energy management is an under explored issue of recognition justice.

Community organisations reported that members and clients are short of knowhow to tackle energy companies and often view their providers as unhelpful. A community energy advisor explained: 'There are crazy situations, like someone getting a bill for $£ 17,000$ instead of the $£ 1,200$ she [an elderly woman] actually owed, and her calls to the company's customer service hadn't resolved the problem-they wouldn't confirm it was an error. As if it wasn't an obvious error-she was living in a small flat not running a factory.' (community organisation energy advisor 1) Workers at the local Citizens Advice Bureau observed that lack of capacity to negotiate with energy companies over 'fuel debt' drove people to fall behind with bills or pay bills by borrowing at high interest from pay day lenders.

Local government and community organisations expressed lack of confidence in retrofitting homes as a panacea for energy vulnerable households. They cited examples, confirmed by our research, of retrofitting schemes leading to complaints of poor quality work or meagre improvement. The most common intervention through assistance schemes was loft insulation, which is a low cost approach to increasing energy efficiency but sometimes added little to levels of thermal comfort: a problem that is frequently exacerbated by cold draughts from windows. 'Thousands of [loft] insulations have been done but it doesn't make much difference [to how people experience their homes] maybe a bit upstairs.' (local authority fuel poverty officer). Replacing windows can improve comfort but fewer replacement programmes were being offered due to cost-benefit calculations that showed the amount of thermal transmittance between one and two panes is not significantly different. These small gains and concerns about standards of work caused energy vulnerable households to lose trust in retrofit providers. So, in this instance attempts to restore distributional 
justice compromised clients' confidence in the possibility for the restoration of procedural justice.

Community organisation staff reported how clients misunderstood energy technologies. During a workshop in 2015 Council staff and members of community organisations demonstrated their agreement with a contributor who commented: 'There is a striking lack of awareness among residents. They do not know how to work their heating or do things that will save them energy.' The borough council's fuel poverty officer's experience of both renters and homeowners revealed a similar 'deficit view' of householders (Catney et al., 2013): 'If people learned how to use their controls, they could make more savings than through a programme supporting retrofitting'. Justification for this view included examples of clients turning off efficient boilers and replacing them with electric fires.

According to the same fuel poverty officer quoted above: 'People complain about fuel bills but they don't adjust things' and a community organisation manager observed that clients feel unable to control their energy expenditure (community organisation manager 2). These problems relate to choosing energy services and providers, but also to managing energy use. We regularly encountered people who were unsure about how to make choices concerning when and how to use energy provision beyond just turning off appliances. We also spoke to energy vulnerable people who preferred to stick to more expensive prepayment cards in order to feel certain about how much they are spending (Ambrose et al., 2016). 'People are happy with meters they can control even if told they are paying four times as much' (community energy advisor 2).

The below table summarises and categorises the issues discussed above to demonstrate how they can be analysed according to the types of injustice identified in the framework for understanding energy vulnerability set out in an earlier section. Our discussion makes clear that there are plenty of overlaps between the categories when applied to research 'on the ground' but that the directly and keenly experienced forms of injustice among energy vulnerable people are forms of distributional and procedural injustice. However, as the next section shows recognition injustice is particularly significant to organisations trying to ensure that those most at risk do not remain invisible. It also illustrates how the design and manner of implementation of energy efficiency schemes can thwart recognition justice. 
p. 38. Assessing and addressing energy vulnerability at the community scale: an interpretive case study

Table 1: The challenges of energy vulnerability in the borough as seen through the lenses of different types of injustice

\begin{tabular}{|c|c|c|}
\hline Lens & Elements & Related Challenges \\
\hline \multirow{8}{*}{$\begin{array}{l}\text { Distributional injustice } \\
\text { - access to } \\
\text { conventional energy } \\
\text { services }\end{array}$} & \multirow[t]{2}{*}{ Low income } & Access to employment \\
\hline & & Navigating benefits and discounts \\
\hline & \multirow[t]{3}{*}{ High energy costs } & $\begin{array}{l}\text { Making choices about suppliers, tariffs and } \\
\text { payment }\end{array}$ \\
\hline & & Debt \\
\hline & & High housing costs \\
\hline & \multirow{3}{*}{$\begin{array}{l}\text { Energy inefficiency in } \\
\text { the home }\end{array}$} & Poor housing quality in general \\
\hline & & $\begin{array}{l}\text { Little control over housing situation - } \\
\text { particularly in private rented sector }\end{array}$ \\
\hline & & Lack of access to support for retrofitting \\
\hline \multirow{3}{*}{$\begin{array}{l}\text { Distributional injustice } \\
\text { - access to low carbon } \\
\text { alternatives (which } \\
\text { can reduce the need } \\
\text { for the conventional } \\
\text { energy services } \\
\text { described above) }\end{array}$} & $\begin{array}{l}\text { Community-owned } \\
\text { renewable energy micro- } \\
\text { generation }\end{array}$ & $\begin{array}{l}\text { Areas most in need have not been able to } \\
\text { seize the opportunities for funding and other } \\
\text { supports to develop these sort of initiatives }\end{array}$ \\
\hline & $\begin{array}{l}\text { Community-produced } \\
\text { food (including growing } \\
\text { and cooking) }\end{array}$ & \multirow[t]{2}{*}{$\begin{array}{l}\text { Broader cultural shifts toward sustainable } \\
\text { lifestyles }\end{array}$} \\
\hline & Transport & \\
\hline \multirow[t]{8}{*}{ Procedural injustice } & \multirow[t]{3}{*}{ Lack of information } & $\begin{array}{l}\text { Understanding bills and money saving } \\
\text { options; technology and support available }\end{array}$ \\
\hline & & $\begin{array}{l}\text { Communication and technological } \\
\text { challenges e.g. ESOL and IT }\end{array}$ \\
\hline & & Lack of awareness of rights \\
\hline & \multirow[t]{3}{*}{ Lack of recourse } & Lack of confidence in dealing with providers \\
\hline & & Unresponsive providers \\
\hline & & Poorly regulated housing and energy sectors \\
\hline & \multirow[t]{2}{*}{ Lack of voice } & $\begin{array}{l}\text { Few mechanisms to participate in policy } \\
\text { processes }\end{array}$ \\
\hline & & Lack of confidence in ability to effect change \\
\hline \multirow[t]{3}{*}{ Recognition injustice } & \multirow{2}{*}{$\begin{array}{l}\text { Unequal cultural and } \\
\text { political respect }\end{array}$} & Increasing inequality and blaming the poor \\
\hline & & Anti-immigrant and racist attitudes \\
\hline & Differences in need & $\begin{array}{l}\text { Reduced public funding to respond to } \\
\text { specific needs }\end{array}$ \\
\hline
\end{tabular}




\section{Constraints and opportunities}

In this section we employ Pratt et al.'s (1999) notion of a working system as people and organisations connecting around a shared purpose. It was this idea that led us to diagnose deficits in delivering solutions to the energy vulnerable residents of the borough - evident from the frustrations reported by paid and volunteer workers delivering initiatives and recipients alike - as emerging from the relations between them. These communication fault lines existed across all aspects of the energy justice model and led to workers operating in organisational silos: whereas whole systems development depends on 'the linking of many varieties of professional knowledge with the local knowledge of people on the ground and in the situation' (Attwood et al., 2003: 28). More optimistically, we also found evidence of growing awareness of the benefits of interconnectedness and the emergence of integrated practices.

\section{Community organisations}

Community organisations had to compete for funding from a range of stop-start schemes that encouraged a patchwork approach and discouraged integrated and collaborative initiatives. Community organisations, or the sub- groups within them dedicated to energy work, were composed of a small number of paid staff and a larger number of volunteers, with volunteers sometimes becoming paid workers for the duration of a particular funded initiative. Personnel of all types moved between groups, also depending on what programmes were running. These transfers attenuated continuity within groups but did forge personal links across the system.

The charting of diverse community initiatives and organisations aimed at ameliorating energy vulnerability in the borough, illustrated a burgeoning eco-system formed from groups, activities and organisations. We saw how some groups and projects were connected in ways that demonstrated potential for promoting flexibility and resilience within a shifting landscape of policy change and short-life funding schemes that typically promoted competition and division. But these connections required strengthening in order to develop a strong, inclusive sector able to nurture meaningful long-term partnerships.

The picture was complex. We discovered that energy is not the sole concern or point of linkage between the Council and community groups, among groups or between groups and their clients, reinforcing Parkhill et al.'s (2015: 69) observation that 'initiatives and policies developed to support energy communities need to be sympathetic to the multiple obligations community members are under while they facilitate the making of sustainable places.'

None of the 17 organisations included in our case study were solely occupied with helping people deal with energy vulnerability. Their energy related activities varied in emphasis but included delivering home energy assessments, advice and the installation of energy efficiency measures. Sometimes households in receipt of these measures were contacted directly by public facing advice sessions in libraries and community centres, but also through the organisations' wider community activities. The latter were significant in building trusting relationships prior to engaging participants in energy programmes and included projects focusing on recreation; nutrition; informal training and skills provision; and socialising. Informants within the community groups acknowledged that households in need of their energy services often remain out of sight. The 'hard to reach' do not necessarily acknowledge recognition injustice in the same ways that they can readily recognise issues of distributional injustice or be encouraged to recognise issues relating to procedural justice. 
Trust gained among borough residents meant community volunteers from one particular organisation were able to accompany council staff or other technical experts on visits in order to make people feel more comfortable about letting a stranger into their home. This was a significant service in addressing the tripartite forms of energy justice, because community organisations were aware that anxiety and isolation leads some people to defect from help from formal sources. A first port of call for some isolated people driven to seek help by financial stress associated with energy bills and fuel debt was the local Citizens Advice. With its trustworthy reputation (Cressey et al., 2014) Citzens Advice was a key entry point for the hard to reach. Several other organisations that address specific audiences, such as mental health charities and organisations working with low income families with young children gave energy advice or made referrals to the local authority.

A downside to the heterogeneity among community groups and the varying degrees to which they addressed energy vulnerability emerged through duplication of activities. Heterogeneity also resulted in competition for funding schemes and in attracting support from a Council in the midst of implementing austerity measures. These factors drove a competitive wedge between organisations that could have gained more from co-operation.

However, such a variety of approaches need not inevitably form impenetrable barriers to creating a holistic system that can respond effectively to the interrelated elements of energy justice. The multifarious nature of community organisations we encountered may even be potentially useful to the pursuit of recognition justice, because it is so difficult for local activists to reach people through energy issues alone. Community organisation staff claimed clients tend not to enter through a door marked 'energy' (community organisation manager 3), rather they seek help due to financial problems related to energy. Community organisations offer alternative entrances through communal meals, gardening, and group activities. It is in these contexts that clients get around to speaking about their experiences of energy vulnerability.

Recognition justice can thus be served by variety within an organisation's portfolio of activities whereby a person or household's energy vulnerability emerges through different forms of engagement. The mixed profiles of the community groups we studied offered opportunities to address different groups and different facets of energy vulnerability, and thus a range of forms of injustice, in integrated ways. But the inchoate nature of cross-group co-operation suggested a need for stronger coordinating activity in the future.

Implementing a holistic approach calls for porous boundaries between groups, while maintaining group identity and volunteer affiliation. For example, sharing skills and routinely making referrals across groups could help to support volunteers and staff from health oriented groups who, when they see the health status of clients affected by fuel poverty, do not feel confident to give energy advice. Similarly, volunteer energy advisors are unfamiliar with tenant-landlord issues. A whole systems approach should also include the creation of a shared database and programme delivery system to coalesce large amounts of information currently held separately by various organisations. Such a data hub would enlarge the knowledge base available to all organisations and generate information that could be usefully shared and analysed for designing innovative solutions. Additionally, information could flow more freely across the intersections with wider systems of energy governance. Thus the 'system of interest' extending across the borough would be strengthened and made more effective than the current sum of its parts. 


\section{The local authority}

The Council occupied an important intermediary position with potential to act as a co-ordinator and facilitator for integrated collaborations within the borough or for developing partnerships that cross municipal boundaries to neighbouring boroughs. An encouraging example was the start of a Council pilot for integrated delivery of assistance to people with multiple problems related to energy vulnerability in collaboration with a programme that originated in an adjacent borough. The pilot aims to offer an individual or household the opportunity for one referral to provide assessment for around thirty potential interventions across a range of social, financial and health problems.

As a major actor within the system, the Council can also apply for funds to provide advice and interventions directly to residents. We observed the disposition of one such project. Several problems arose. The referral of households to receive material interventions was cumbersome and negatively affected by weak relationships between the incumbent fuel poverty officer and other Council teams and with community organisation partners. It was sometimes hard to understand how criteria for eligibility for interventions were being met. Pressure to fulfil quotas within the time frame of the project meant that decisions were too often made in haste. The eligibility criteria for the scheme included different types of energy vulnerable households, including young families, but the recruitment process targeted people in receipt of pension credit, which effectively excluded young families and promoted a stereotype that equates energy vulnerability with 'images of the "old and cold"' (Gillard et al., 2017: 54).

Misrecognition was inherent in this scheme's design and delivery. Advertising the benefits available to residents was not well targeted. It focused on a mailing sent to residents appearing in the first one hundred in a list of postcodes, including better off neighbourhoods. These practices disappointed community organisation partners who could not understand why candidates they proposed for the scheme were being overlooked. Their frustration prompted some of them to criticise the Council and disengage from the scheme.

Energy Performance Certificates were available as tools for identifying potentially effective interventions within the scheme. But, although being accessible on-line, they were rarely used by the incumbent fuel poverty officer to facilitate decisions on technical interventions. In cases where loft insulation was recommended some lofts turned out to be brimming with obstructive items and where residents could not act on their own behalf to remove the offending items, no help was available, leading to the intervention being abandoned. Clutter in homes sometimes interfered with the efficient operation of heating systems. But the amelioration of this problem could not be provided under remits for assistance by the Council. Community organisations were not consulted to see if they could provide help.

Efforts to address distributive injustice did not account for its connection to procedural injustice. Funding opportunities directed toward tangible actions that facilitated carbon and cost savings, such as replacement boilers and solid wall insulation schemes were not always realised by recipients due to deficiencies with installation or failure to ensure that residents were properly instructed in how to use new technologies. Even when appropriately installed, these high-cost measures appeared to reach only a restricted group of people and did nothing towards resolving injustices of recognition.

Centralised funding systems adopt a nationwide approach that cannot be adapted to address local needs. For example, the government's flagship Green Deal programme, a home retrofitting scheme based on loans ran for only two years (2013- 
2015) before being scrapped. ${ }^{1}$ The programme's potential for alleviating energy vulnerability in the poorest neighbourhoods of the case study borough was minimal. The conditions it enforced were too constraining for people with low incomes; particularly the cash contribution from occupiers and the high levels of interest on the accompanying loan (Thorpe, 2016; Marchand et al., 2015; Pettifor et al., 2015; Dowson et al., 2012).

The Energy Company Obligation (ECO) is a government policy obliging large scale energy suppliers to help households become energy efficient. Within ECO, the Home Heating Cost Reduction Obligation focuses specifically on vulnerable households. In our case study area, fulfilment of this obligation primarily resulted in replacement of boilers. A complementary scheme, the Warm Home Discount (WHD) scheme places a legal obligation on suppliers to provide discounts on energy bills. The government further provides Winter Fuel Payments and Cold Weather Payments. While these interventions are important, we found that energy vulnerable households received subsidies that temporarily alleviated their problems instead of providing enduring solutions that increased the energy efficiency of their homes. The government is currently shifting the overall focus of ECO to the most energy vulnerable households and introducing greater flexibility for local authorities to define eligibility criteria to reflect local needs (BIES, 2017c).

In our case study location the Council is engaging in dialogue with government concerning how to define effective eligibility criteria for ECO, and working more closely with community organisations to identify priority households and effective approaches. It hopes in this way to overcome dependence on ill-fitting centralised funding opportunities. The Council is looking to formulate a strategy based on an understanding of the specific system in which they all operate and how it might be improved. This shift has been made more feasible by our collaborative research, which revealed the contours of a broader system that was previously only partially perceptible to those who participated in it.

\section{Discussion and conclusion}

Together, the Council, community organisations, businesses and housing and energy providers should be able to ensure that energy vulnerable people are provided with ongoing, joined-up support that increases their confidence and capacity in relation to energy issues by connecting them to a broader community pursuing collective goals relating to health, well-being and low-carbon transition. To achieve this outcome the Council should maintain an accurate overview of the full range of community assets that exist in the borough at any one time by updating the system map that was put in place during our research. It should also stay informed about the diversity of the work of community organisations in order to co-ordinate and facilitate relations between them.

One important policy challenge on the horizon is the introduction of minimum energy efficiency standards as part of the new fuel poverty strategy for England (DECC, 2015). The goal is 'to ensure that as many fuel poor homes as is reasonably practicable achieve a minimum energy efficiency standard of Band C, by 2030' (DECC, 2015: 7). It includes a requirement for landlords to "bring their homes up to a minimum E level EPC rating or, from the 1st April 2018, not be able to let out their properties' (ibid.). These standards offer a vehicle for addressing the private rental sector, as one of the main locations for energy vulnerability. However, the new measures raise obstacles to procedural justice in relation to regulation and enforcement, and in motivating landlords, who will not be obliged to make the 
necessary improvements unless they are eligible for funding by government schemes. Community organisations have a key role to play in educating and empowering tenants to ensure effective implementation of the new policy given the history of noncompliance on the part of landlords and lack of awareness on the part of tenants with respect to Energy Performance Certificates.

Above all the Council should work with grass roots organisations to improve its comprehension of recognition justice. These organisations are keenly aware of its importance, as illustrated by those that concentrated on unearthing hidden pockets of energy vulnerability and creating a rapport with clients 'grounded in their own contexts and trusting relationships' (Catney et al., 2013: 507). Without such attention to recognition justice people in need continue to suffer distributive and procedural injustice.

A whole systems approach can provide an alternative for the diagnosis and treatment of problems at local level. We found it effective as a tool for identifying imperatives 'for implementation of sustainable change, rather than mere interventions to "fix" problems' (Atwood et al., 2003: 2). Single interventions to address energy vulnerability in households, like retrofitting, can and do work in certain circumstances, but it is mistaken to assume that they provide a cure all or that they are distributed across the full range of households that might benefit from them. As outlined in our findings, focusing on relations between elements of the whole system shows how certain interactions, or lack of, can conspire to push decisions and practices towards predictable and limited measures that offend against recognition justice in particular.

Without recognition justice people remain divorced from distributional and procedural justice. However, recognition justice is hard to achieve because it involves a highly nuanced understanding of people's responses to their circumstances and requires detailed understanding of the specific and varied needs within young families and among elderly or disabled people (Middlemiss and Gillard, 2015). People at risk of energy vulnerability need regular persistent support to ensure they get the best out of interventions as their own energy requirements change alongside external factors. The loss of employment by a member of a low income family, disabled people undergoing a spell in hospital or an elderly person's inability to manage their home following the death of a partner can coincide with extra cold winters or price rises to confound people's circumstances. Protecting people from energy vulnerability is an iterative process that depends on practitioners maintaining an integrated overview of the communities they serve and creating links between the constellation of organisations and activities involved.

* Correspondence address: Prof. Sandra Bell, Department of Anthropology, Durham University, DH1 4AX. UK. Email: sandra.bell@durham.ac.uk 


\section{References}

Adams, C. A. and Bell, S. (2015) Local energy generation projects: assessing equity and risks. Local Environment, 20, 12, 1473-1488.

Adams, C., Taylor, P. and Bell, S. (2012) Equity dimensions of micro-generation: A whole systems approach. Journal of Renewable and Sustainable Energy, 4, 5, 053122.

Ambrose, A., McCarthy, L. and Pinder, J. (2016) Energy (in)efficiency: What tenants expect and endure in private rented housing. Sheffield: CRESR, Sheffield Hallam University. Available at:

https://www4.shu.ac.uk/research/cresr/sites/shu.ac.uk/files/energyinefficiency-private-rented-housing-final-report.pdf [Accessed: 22/05/2018].

Attwood, M., Pedler, M. and Pritchard, S. (2003) Leading change: A guide to whole systems working. Bristol: Policy Press.

Boardman, B. (1991) Fuel poverty: from cold homes to affordable warmth. Pinter Pub Limited.

Boardman, B. (2013) Fixing fuel poverty: challenges and solutions. Routledge.

Boardman, J. and Sauser, B. (2008) Systems thinking: Coping with 21st century problems. Boca Raton, FL: CRC Press.

Bone, J. (2014) Neoliberal Nomads: Housing Insecurity and the Revival of Private Renting in the UK. Sociological Research Online, 19, 4.

Bouzarovski, S. and Petrova, S. (2015) A global perspective on domestic energy deprivation: Overcoming the energy poverty-fuel poverty binary. Energy Research \& Social Science, 10, 31-40.

Bouzarovski, S., Petrova, S. and Tirado-Herrero, S. (2014) From Fuel Poverty to Energy Vulnerability: The Importance of Services, Needs and Practices. SPRU-Science and Technology Policy Research, University of Sussex. Available at: https://ideas.repec.org/p/sru/ssewps/2014-25.html [Accessed: 10/08/17].

Cressey, P., Milner, S., Farr, M., Abercrombie, N. and Jaynes, B. (2014) IPR Policy Brief Proving the value of advice: a study of the impact of Citizens' Advice Bureau services. University of Bath.

Catney, P., Dobson, A., Hall, S.M., Hards, S., MacGregor, S., Robinson, Z., Omerod, M. and Ross, S. (2013) Community knowledge networks: An action-oriented approach to energy research. Local Environment, 18, 4, 506-520.

Day, R. and Walker, G. (2013) Household vulnerability as 'assemblage'. In: Bickerstaff, K., Walker, G. and Bulkekley, H. (eds) Energy justice in a changing climate: Social equity and low-carbon energy. London: Zed books: 91-115.

Department for Business, Energy and Industrial Strategy (BEIS) (2017a) Sub-regional fuel poverty data 2017 (2015 data). Available at: https://www.gov.uk/government/statistics/sub-regional-fuel-poverty-data-2017 [Accessed: 10/05/2018].

Department for Business, Energy and Industrial Strategy (BEIS) (2017b) Annual Fuel Poverty Report, England (2015 data). Available at: https://assets.publishing.service.gov.uk/government/uploads/system/uploads/a ttachment_data/file/639118/Fuel_Poverty_Statistics_Report_2017_revised_Aug ust.pdf [Accessed: 20/05/2018].

Department of Energy and Climate Change (DECC) (2015) Cutting the cost of keeping warm - a fuel poverty strategy for England. Department of Energy \& Climate Change. Available at:

https://www.gov.uk/government/uploads/system/uploads/attachment_data/file 4408644/cutting the cost of keeping warm.pdf [Accessed: 10/08/17].

Dowson, M., Harrison, D. and Susman, G. (2012) Domestic UK retrofit challenge: Barriers, incentives and current performance leading into the Green Deal. Energy Policy, 50, 294-305. 
Fischer, J., Constanza, E., Ramcharn, S.D. and Coley, L. (2014) Energy advisors at work: Charity work practices to support people in fuel poverty. Ubicomp'14 Proceedings of the 2014 ACM International Joint Conference on Pervasive and Ubiquitous Computing. Seattle, WA. Available at: http://dl.acm.org/citation.cfm?id=2632048 [Accessed: 10/08/17].

Gillard, R., Snell, C. and Brown, M. (2017) Advancing an energy justice perspective of fuel poverty: household vulnerability and domestic retrofit policy in the United Kingdom. Energy Research and Social Science, 29, 53-61.

Goldthau, A., and Sovacool, B. (2012) The uniqueness of the energy security, justice and governance problem. Energy Policy, 41, 232-240.

Grey, C. N. B., Jiang, S., Nascimento, C., Rodgers, S.E., Johnson, R., Lyons, R. A. and Poortinga, W. (2017) The short-term health and psychosocial impacts of domestic energy efficiency investments in low-income areas: a controlled before and after study. BMC Public Health, 17, 1, 140.

Ison, R.L. (2008) Systems thinking and practice for action research. In: Reason, P.W. and Bradbury, H. (eds) The Sage Handbook of Action Research Participative Inquiry and Practice (2nd edition). London: Sage Publications, 139-158.

Jenkins, K., McCauley, D., Heffron, R. and Hannes, S. (2014) Energy justice: a whole systems approach. Queen's Policy Review, 2, 2, 74-87.

Marchand, R. D., Koh, S. C. L. and Morris, J. C. (2015) Delivering energy efficiency and carbon reduction schemes in England: Lessons from Green Deal Pioneer Places. Energy Policy, 84, 96-106.

Middlemiss, L. and Gillard, R. (2015) Fuel Poverty from the bottom-up: Characterising household energy vulnerability through the lived experience of the fuel poor. Energy Research and Social Science, 6, 146-154.

Ministry of Housing, Communities and Local Government (MHCLG) (2017) English Housing Survey Private Rented Sector Report, 2015-16. Available at: https://assets.publishing.service.gov.uk/government/uploads/system/uploads/a ttachment_data/file/627686/Private_rented_sector_report_2015-16.pdf [Accessed 10/05/18].

National Energy Action (NEA) (2015) An introduction to energy awareness and fuel poverty. National Energy Action. Available at: http://www.nea.org.uk/training/course-outlines/an-introduction-to-energyawareness-and-fuel-poverty-1-day/ [Accessed: 10/08/17].

Parkhill, K.A., Shirani, F., Butler, C., Henwood, K.L., Groves, C. and Pidgeon, N.F. (2015) 'We are a community [but] that takes a certain amount of energy': Exploring shared visions, social action, and resilience in place-based community-led energy initiatives in Environmental Science \& Policy, 53, 60-69.

Pearson, P. and Watson, J. (2012) UK Energy Policy 1980-2010: A history and lessons to be learnt. The Parliamentary Group for Energy Studies. Available at: http://sro.sussex.ac.uk/38852/1/uk-energy-policy.pdf [Accessed: 09/08/17].

Pettifor, H., Wilson, C. and Chryssochoidis, G. (2015) 'The appeal of the green deal: Empirical evidence for the influence of energy efficiency policy on renovating homeowners'. Energy Policy, 79, 161-176.

Pratt, J., Gordon, P. and Plamping, D. (1999) Working whole systems: putting theory into practice. London: Kings Fund.

Reeves, A. (2016) Exploring local and community capacity to reduce fuel poverty: The case of home energy advice visits. Energies, 9, 276.

Rugkåsa, K., Shortt, N. and Boydell, L. (2007) The right tool for the task: "boundary spanners' in a partnership approach to tackle fuel poverty in rural Northern Ireland. Health and Social Care, 15, 3, 221-230.

Simcock, N., Walker, G. and Day R. (2016) Fuel Poverty in the UK; beyond heating? People Place and Policy, 10, 1, 25-41. 
Shortt, N. and Rugkåsa, J. (2007) 'The walls were so damp and cold.' Fuel poverty and ill health in Northern Ireland: Results from a housing intervention. Health and Place, 13, 1, 99-110.

Thorpe, D. (2016) Why the UK Green Deal failed and why it needs a replacement. Energy Post, [online] Available at: http://www.energypost.eu/uk-green-deal-failedneeds-replacement/ [Accessed: 20/05/2018].

Walker, G. and Day, R. (2012) Fuel poverty as injustice: Integrating distribution, recognition and procedure in the struggle for affordable warmth. Energy Policy, $49,69-75$. 